\title{
New Data Show U.S. Birth Rate Hits Record Low
}

Kenneth M. Johnson

$\mathrm{N}$ ew data from the National Center for Health Statistics show a record low birth rate in the United States. In 2016, I estimate there were 600,000 fewer births in the United States than would have been expected had pre-recessionary birth rates continued. And, there is no evidence in these new data that this birth dearth is diminishing. The Great Recession sent an economic shock through American society that reached far beyond the stock and housing market. One substantial long-term impact of the Great Recession is that more than four million fewer babies were born in the United States between 2008 and 2016 than would have been expected had pre-recession fertility rates among women of child-bearing age been sustained. Fewer births are occurring now even though there are more women of prime child-bearing age. The result is empty cradles in maternity wards and fewer children in kindergarten classrooms.

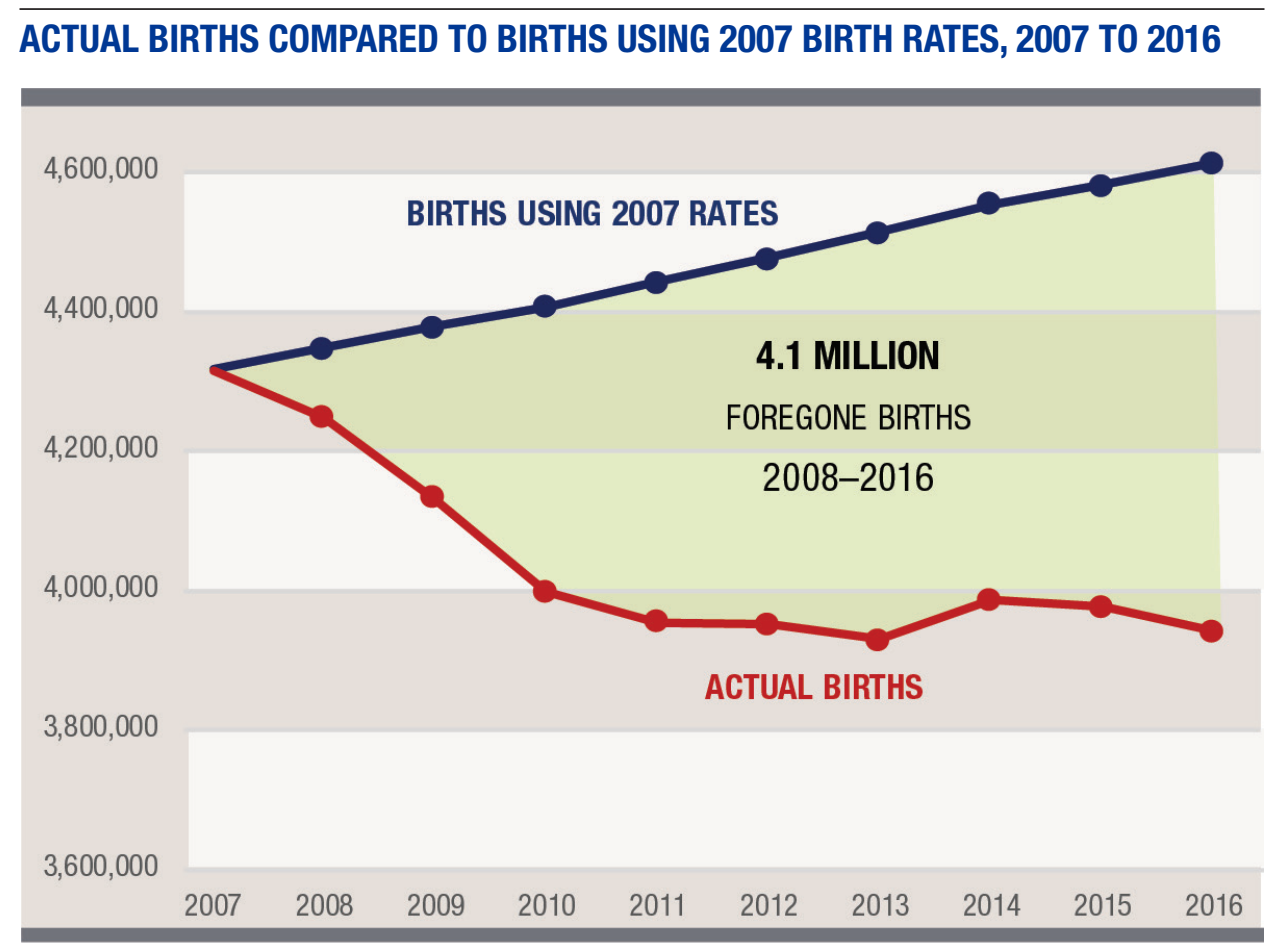

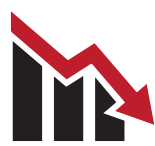

The Great Recession officially lasted from December 2007 to June 2009, but it continues to influence U.S. demographic trends.

See Related Publications at carsey.unh.edu

- June 2016, U.S. Births Remain Low as the Great Recession Wanes: More Than Three Million Fewer Births and Still Counting

December 2014, The Hidden Cost of the Recession: Two Million Fewer Births and Still Counting

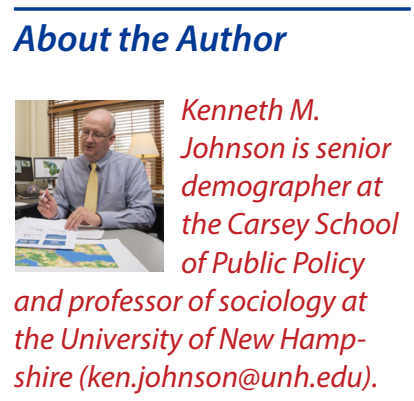

Analysis: K.M. Johnson, Carsey School, University of New Hampshire Data: National Center for Health Statistics and U.S. Census Bureau

Huddleston Hall • 73 Main Street • Durham, NH 03824 This piece is printed on Mohawk 100\% recycled paper carsey.unh.edu • 603.862.2821

TTY USERS: DIAL 7-1-1 OR 1-800-735-2964 (RELAY N.H.) 